\title{
Perbandingan Pemulihan Laju Jantung antara Subjek Obes Sentral Terlatih dengan yang Non-obes Sentral Tak Terlatih
}

\author{
${ }^{1}$ Ribka Wowor \\ ${ }^{2}$ Frans Wantania \\ ${ }^{2}$ Fendy Pamolango
}

\author{
${ }^{1}$ Fakultas Kesehatan Masyarakat Universitas Sam Ratulangi Manado \\ ${ }^{2}$ Bagian Ilmu Penyakit Dalam Fakultas Kedokteran Universitas Sam Ratulangi \\ BLU RSUP Prof. Dr. R. D. Kandou Manado \\ Email: ribkaladywowor@gmail.com
}

\begin{abstract}
Heart rate recovery (HRR) is a predictor of cardiovascular mortality in adult as well as a risk factor of diabetes mellitus and cardiovascular diseases. Heart rate recovery is affected by autonomic nerve system and interestingly, athletes have more effective autonomic nerve system than the non-athletes. This was an observational descriptive study with a crosssectional design. Subjects were 15 adult trained males with central obesity and 15 untrained males without central obesity. Central obesity was determined if abdominal circumferences was above $90 \mathrm{~cm}$. The treadmill test with Bruce protocol was used to evaluate the HHR at the second minute of recovery which was abnormal if the HRR below 42 times per minute. The non-tailed $\mathrm{T}$ test was used to determine the comparison of HRR between trained central obese and non-trained non-central obese subjects. The results showed that the 15 trained males with central obesity had average age $31.7 \pm 3.7$ years and mean abdominal circumference $98.6 \pm 5.66$ $\mathrm{cm}$ meanwhile the 15 untrained males without central obesity had mean age $29.4 \pm 6.4$ years and mean abdominal circumference $80.27 \pm 7.05 \mathrm{~cm}$. Mean HRR of the trained subjects was $55.6 \pm 10.6$ and of the untrained subjects was $47.8 \pm 1.8$. The non-tailed $\mathrm{T}$ test showed significant result in comparing the HRR between trained subjects and untrained subjects $(P<$ 0.025). Abnormal HRR was found in $6.6 \%$ of the trained subjects and in $20 \%$ of the untrained subjects. Conclusion: Trained males with central obesity had a better HRR significantly than untrained males without central obesity; therefore, physical exercise played an important role in HRR.
\end{abstract}

Keywords: heart rate recovery (HRR), central obesity, trained

\begin{abstract}
Abstrak: Pemulihan laju jantung (PLJ) merupakan prediktor kematian kardiovaskular pada orang dewasa dan dipengaruhi oleh sistem saraf otonom. Uniknya, atlet atau individu yang terlatih memiliki sistem saraf otonom yang lebih efektif dibandingkan dengan yang tidak terlatih. Jenis penelitian ialah deskriptif observasional dengan desain potong lintang. Subjek penelitian terdiri dari15 pria dewasa dengan obesitas sentral yang terlatih dan 15 pria dewasa dengan non-obesitas sentral yang tidak terlatih. Subjek dinyatakan terlatih bila memenuhi rekomendasi latihan fisik menurut WHO. Obesitas sentral diukur dengan meteran pada lingkar perut bila lebih dari $90 \mathrm{~cm}$. Uji latih jantung (ULJ) menggunakan treadmill dengan protokol Bruce. Pemulihan laju jantung dinilai pada menit ke-2 fase pemulihan dan dikatakan abnormal bila PLJ $<42 \mathrm{x} /$ menit. Perbandingan antara PLJ pada subjek obes sentral yang terlatih dengan subjek non-obes sentral yang tidak terlatih diuji dengan uji-T tidak berpasangan. Hasil penelitian mendapatkan 15 subjek pria obes sentral yang terlatih dengan rerata usia $31,7 \pm 3,7$ tahun, rerata lingkar perut $98,6 \pm 5,66 \mathrm{~cm}$ dan 15 subjek pria non-obes sentral yang tidak terlatih dengan rerata usia $29,4 \pm 6,4$ tahun, rerata lingkar perut $0,27 \pm 7,05 \mathrm{~cm}$. Rerata PLJ pada subjek obes sentral yang terlatih 55,6 $\pm 10,6$, dan rerata PLJ pada non-obes sentral yang tidak terlatih
\end{abstract}


47,8 $\pm 1,8$. Uji-T tidak berpasangan mendapatkan hasil bermakna untuk perbandingan antara PLJ pada subjek obes sentral yang terlatih dengan subjek non-obes sentral yang tidak terlatih ( $<<0,025)$. Didapatkan nilai abnormal PLJ 6,6\% pada kelompok subjek obes sentral terlatih dan 20,0\% pada kelompok subjek non-obes sentral tak terlatih. Simpulan: Subjek obes sentral yang terlatih memiliki PLJ yang lebih baik dibandingkan dengan subjek non-obes sentral yang tidak terlatih secara bermakna yang menunjukkan faktor latihan fisik berperan penting terhadap PLJ.

Kata kunci: pemulihan laju jantung (PLJ), obesitas sentral, terlatih

Pemulihan laju jantung (PLJ) merupakan penurunan denyut jantung setelah latihan fisik serta sebagai prediktor independen terhadap mortalitas akibat kardiovaskular dan faktor risiko pada penyakit kardiovaskular. ${ }^{1}$ Keterlambatan dari PLJ telah digunakan sebagai petanda dari disfungsi autonom. Hal ini juga dapat merupakan tanda dari kerusakan miokard jantung. ${ }^{2}$ Pemulihan laju jantung dihasilkan oleh kombinasi aktivasi saraf simpatis dan deaktivasi saraf parasimpatis. ${ }^{3}$ Stimulasi simpatis berlebihan akan meningkatkan kerja sistem kardiovaskular, memberi beban terhadap hemodinamik tubuh serta merupakan predisposisi terjadinya disfungsi endotel, spasme koroner, hipertrofi ventrikel kiri, serta disritmia, termasuk kejadian henti jantung mendadak melalui instabilitas listrik jantung. ${ }^{2}$ Peningkatan dari PLJ berkorelasi dengan penurunan berat badan, indeks massa tubuh (IMT), lingkar perut, kadar trigliserida, rasio trigliserida/HDL, dan kadar gula darah. Kesemuanya ini merupakan faktor yang dapat dimodifikasi untuk meningkatkan PLJ setelah latihan fisik. ${ }^{1}$

Obesitas telah dibuktikan merupakan faktor risiko yang penting dalam penyakit kardiovaskular. ${ }^{3}$ Tingginya IMT berkaitan dengan gangguan pada PLJ setelah latihan fisik; hal ini menunjukkan disfungsi dari nervus vagus pada individu dengan IMT yang tinggi. ${ }^{4}$ Terdapat perbaikan pada PLJ setelah latihan fisik pada individu obes yang diberikan latihan fisik selama 3 bulan dan program penurunan berat badan. ${ }^{5}$

Penurunan PLJ kurang dari 21-23 denyut tiap menit disertai dengan peningkatan mortalitas secara bermakna. ${ }^{6}$ Pemulihan laju jantung dikatakan abnormal jika PLJ pada fase pemulihan menit ke-2 $<42 \mathrm{x} /$ menit. ${ }^{7}$ Latihan fisik yang direkomendasikan oleh WHO pada usia 18-64 tahun ialah 150 menit per minggu latihan dengan intensitas sedang (bersepeda, jalan cepat) atau 75 menit per minggu latihan dengan intensitas tinggi (sepakbola, basket), durasi setiap latihan paling kurang 10 menit. $^{8}$ Terdapat hubungan terkait antara PLJ dengan tingkat ketahanan kardiovaskular dan intensitas dari latihan fisik. ${ }^{9}$ Atlet yang terlatih memiliki dimensi kapasistas ventrikel kiri akhir distolik $6 \%$ dan ketebalan dinding $40 \%$ lebih tinggi daripada yang tidak terlatih. ${ }^{10}$

Penelitian ini bertujuan untuk mengetahui perbandingan PLJ antara subjek obes sentral yang terlatih dengan subjek non-obes yang tidak terlatih.

\section{METODE PENELITIAN}

Jenis penelitian ini ialah deskriptif observasional dengan desain potong lintang. Subjek penelitian ialah 15 pria dewasa dengan obesitas sentral yang terlatih dan 15 pria dewasa non-obesitas sentral yang tidak terlatih. Penelitian dilakukan pada bulan Juli 2015 di bagian Ilmu Penyakit Dalam RSUP Prof. Dr. R. D. Kandou Maando. Kriteria inklusi pada penelitian ini ialah pria dewasa usia 20-50 tahun, obesitas sentral yang terlatih, nonobesitas yang tidak terlatih, dan bersedia menandatangani informed consent. Kriteria ekslusi pada penelitian ini ialah subjek dengan penyakit jantung koroner, menggunakan alat bantu jalan, penyakit kardiovaskular, penyakit otot dan sendi, dan menolak mengikuti penelitian.

Obesitas sentral diukur dengan meteran pada lingkar perut $>90 \mathrm{~cm}$ pada 
pria dewasa. Uji latih jantung dilakukan dengan treadmill menggunakan protokol Bruce. Subjek yang terlatih ditentukan melalui kategori oleh WHO dengan Global Recommendations on Physical Activity for Health pada usia 18-64 tahun. Pemeriksaan ULJ dihentikan bila terdapat keluhan, tercapai target laju nadi maksimal (220usia dalam tahun), atau bila didapatkan tanda atau gejala yang merupakan indikasi untuk menghentikan ULJ seperti: nyeri dada, sesak nafas, tekanan darah turun $>20$ $\mathrm{mmHg}$, respons hipertensi dan artimia persisten. Pemeriksaan PLJ dikatakan abnormal jika didapatkan PLJ <42x/menit pada fase pemulihan menit ke-2 setelah ULJ.

Analisis hasil dilakukan dengan menggunakan aplikasi SPSS 22.0, dan dilakukan uji korelasi antara nilai masingmasing pemeriksaan.

\section{HASIL PENELITIAN}

Kenormalan data PLJ diuji menggunakan uji Kolmogorov-Smirnov dengan hasil data terdistribusi normal (Tabel 1).

Tabel 1. Uji kenormalan data

One-Sample Kolmogorov-Smirnov Test

\begin{tabular}{llc}
\hline & & PLJ \\
\hline $\mathrm{N}$ & & 30 \\
Normal & Mean & 51,73 \\
Parameters & Std. Deviation & 9,770 \\
Most extreme & Absolute &, 142 \\
differences & Positive &, 142 \\
& Negative &,- 118 \\
Test Statistic & &, 142 \\
Asymp. Sig. (2-tailed) &, $129^{\mathrm{c}}$ \\
\hline
\end{tabular}

a. Test distribution is normal.

b. Calculated from data.

c. Lilliefors Significance Correction.

Tabel 2. Data rerata subjek

\begin{tabular}{lccc}
\hline Kelompok & Mean & N & Std. Deviation \\
\hline Usia & & & \\
$\bullet \quad$ Obesitas yang terlatih & 31,73 & 15 & 3,788 \\
- Non-obesitas yang tidak terlatih & 29,47 & 15 & 6,788 \\
- Total & 30,60 & 30 & 5,328 \\
Lingkar perut & & & \\
- Obesitas yang terlatih & 98,60 & 15 & 5,667 \\
- Non-obesitas yang tidak terlatih & 80,27 & 15 & 7,056 \\
- Total & 89,43 & 30 & 11,245 \\
Tekanan darah sistolik & & & \\
- Obesitas yang terlatih & 122,00 & 15 & 15,657 \\
- Non-obesitas yang tidak terlatih & 115 & 15 & 11,255 \\
- Total & 118,67 & 30 & 13,830 \\
Tekanan darah distolik & & & \\
- Obesitas yang terlatih & 78,67 & 15 & 5,164 \\
- Non-obesitas yang tidak terlatih & 73,33 & 15 & 8,165 \\
- Total & 76,00 & 30 & 7,240 \\
Nadi post-treadmill t0 & & & \\
$\bullet \quad$ Obesitas yang terlatih & 184,47 & 15 & 7,791 \\
- Non-obesitas yang tidak terlatih & 184,07 & 15 & 7,025 \\
- Total & 184,27 & 30 & 7,292 \\
Nadi Post-treadmill t2 & & & \\
- Obesitas yang terlatih & 128,80 & 15 & 7.571 \\
- Non-obesitas yang tidak terlatih & 136,27 & 15 & 9.377 \\
- Total & 132,53 & 30 & 9.194 \\
\hline
\end{tabular}


Tabel 3. Proporsi abnormalitas PLJ pada kelompok dengan obesitas sentral terlatih dan non-obesitas sentral tak terlatih

\begin{tabular}{lccc}
\hline \multirow{2}{*}{ PLJ } & \multicolumn{2}{c}{ Kelompok } & P \\
\cline { 2 - 3 } & $\begin{array}{c}\text { Obes sentral terlatih } \\
(\mathrm{N}=15)\end{array}$ & $\begin{array}{c}\text { Non-obes sentral } \\
\text { tak terlatih }(\mathrm{N}=15)\end{array}$ & \\
\hline PLJ menit ke-2 & $1(6,6 \%)$ & $3(20,0 \%)$ & 0,299 \\
\hline
\end{tabular}

Analisis dengan chi-square

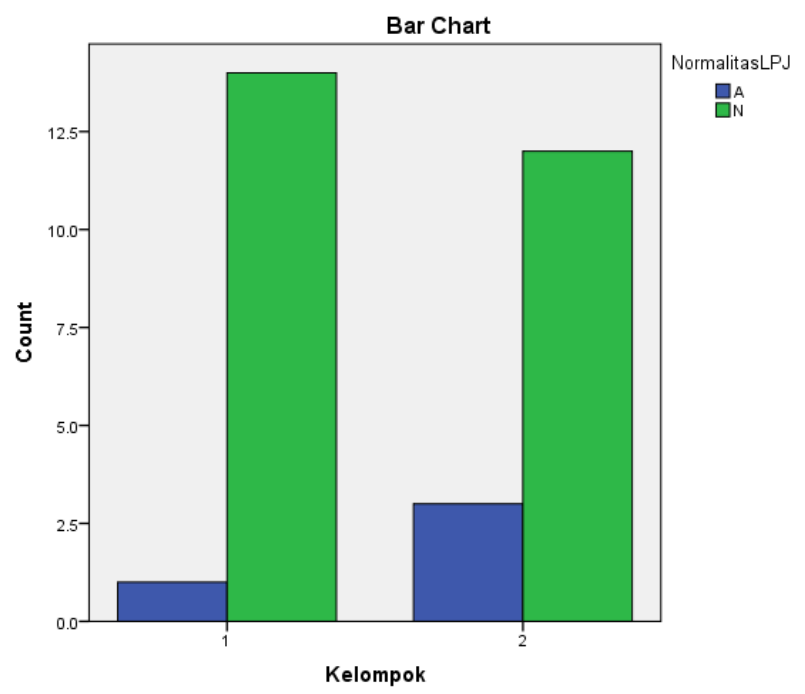

*Kelompok 1: Obes sentral terlatih ; Kelompok 2: Non-obes sentral tak terlatih

Tabel 4. Perbandingan PLJ pada kelompok obes sentral terlatih dan non-obes tak terlatih

\begin{tabular}{lcccc}
\hline Kelompok & N & Mean & Std. Deviation & Std. Error mean \\
\hline Obes sentral terlatih & 15 & 55,67 & 10,648 & 2,749 \\
Non-obes sentral tak terlatih & 15 & 47,80 & 7,153 & 1,847 \\
\hline
\end{tabular}

\begin{tabular}{|c|c|c|c|c|c|c|c|c|c|}
\hline \multirow[b]{3}{*}{ PLJ } & \multicolumn{2}{|c|}{$\begin{array}{l}\text { Levene's } \\
\text { Test Eq of } \\
\text { Variances }\end{array}$} & \multicolumn{7}{|c|}{ t-test for Equality of Means } \\
\hline & \multirow[t]{2}{*}{$\mathrm{F}$} & \multirow[t]{2}{*}{ Sig. } & \multirow[t]{2}{*}{$\mathrm{t}$} & \multirow[t]{2}{*}{ df } & \multirow[t]{2}{*}{$\begin{array}{l}\text { Sig.(2- } \\
\text { tailed) }\end{array}$} & \multirow[t]{2}{*}{$\begin{array}{c}\text { Mean } \\
\text { Difference }\end{array}$} & \multirow[t]{2}{*}{$\begin{array}{l}\text { Std. Error } \\
\text { Difference }\end{array}$} & \multicolumn{2}{|c|}{$\begin{array}{c}\text { 95\% Conf.Interval of } \\
\text { the difference }\end{array}$} \\
\hline & & & & & & & & Lower & Upper \\
\hline $\begin{array}{l}\text { Equal } \\
\text { Variances } \\
\text { assumed }\end{array}$ & 2,671 & ,113 & 2,375 & 28 & ,025 & 7,867 & 3,312 & 1,082 & 14,651 \\
\hline $\begin{array}{l}\text { Equal } \\
\text { variances not } \\
\text { assumed }\end{array}$ & & & 2,375 & 24,49 & ,026 & 7,867 & 3,312 & 1,038 & 14,695 \\
\hline
\end{tabular}

Terdapat 15 subjek pria obes sentral yang terlatih dengan rerata usia $31,7 \pm 3,7$ tahun dan 15 subjek pria non-obes sentral yang tidak terlatih dengan rerata usia 29,4 $\pm 6,4$ tahun. Rerata PLJ pada subjek obes sentral terlatih $55,6 \pm 10,6$, dan rerata PLJ pada non-obes sentral tak terlatih
47,8 $\pm 1,8$. Pada uji-T tidak berpasangan didapatkan hasil yang bermakna untuk perbandingan antara PLJ pada subjek obes sentral terlatih dengan subjek non-obes sentral tak terlatih $(P<0,025)$, yang menunjukkan semakin terlatih seseorang semakin baik nilai PLJ. Didapatkan 
presentasi abnormal PLJ 6,6\% pada subjek obes sentral terlatih dan $20,0 \%$ pada subjek non-obes sentral tak terlatih.

\section{BAHASAN}

Pemulihan laju jantung setelah melakukan latihan sangat berkaitan dengan kondisi kebugaran fisik seseorang. Semakin baik tingkat kebugaran fisik seseorang maka waktu PLJ yang dicapai lebih cepat. Beberapa studi menyatakan bahwa waktu PLJ dapat digunakan untuk keperluan diagnostik dan prognostik, terutama dalam penyakit kardiovaskular bahkan dalam kematian mendadak. ${ }^{11,12}$

Dalam proses latihan dan PLJ merupakan rangkaian simultan aktivasi simpatis dan parasimpatis. Saat latihan aktivitas simpatis berperan dan sebaliknya pada saat pemulihan parasimpatis yang lebih berperan, namun dikatakan bahwa satu sama lain tidak dapat dipisahkan dalam peran selama latihan maupun pemulihan. ${ }^{11}$ Peningkatan aktivitas simpatis dan penurunan aktivitas parasimpatis yang timbul pada gagal jantung secara klinis memiliki relevansi dengan progresivitas penyakit serta mortalitas pasien dengan gagal jantung kronis. Stimulasi simpatis yang berlebihan meningkatkan kerja sistem kardiovaskular, memberi beban terhadap hemodinamik tubuh, serta merupakan predisposisi terjadinya disfungsi endotel, spasme koroner, hipertrofi ventrikel kiri, disritmia dan henti jantung mendadak. ${ }^{13}$

Selama latihan, parameter kardiovaskular berubah untuk menyediakan pasokan oksigen pada otot yang sedang bekerja dan untuk memelihara perfusi oksigen ke organ vital. Tahanan vaskular dan denyut jantung dikontrol secara terpisah saat aktivitas fisik. Pada saat peningkatan tingkat aktivitas dan denyut jantung sekitar $100 \mathrm{x} /$ menit, aktivitas simpatik akan segera meningkat sehingga denyut jantung akan semakin meningkat dan juga disertai peningkatan konsentrasi norepinefrin plasma dan vasokonstriksi pembuluh darah pada organ perifer. Pada saat fase pemulihan terjadi aktivasi baroreseptor sehingga meningkatkan aktivasi parasimpatis yang akan menurunkan denyut jantung walaupun simpatis masih aktif. ${ }^{14}$

Kontrol eferan parasimpatis pada denyut jantung diperantarai oleh rangsangan kolinergik pada nodus sinoartrial. Penghambat asetilkolinesterase dapat meningkatkan neurotransmiter parasimpatis dengan merusak enzim yang akan merubah asetilkolin menjadi kolinergik. Penelitian yang dilakukan oleh Dewland et al. ${ }^{15}$ dengan memberikan piridostigmin, yaitu suatu penghambat asetilkolinesterase, dapat meningkatkan PLJ. Hal ini menunjukkan adanya suatu keadaan jenuh atau traininginduced ceiling effect akibat efek mekanisme umpan balik dalam upaya mempertahankan hemostasis. Ceiling effect dari sistem parasimpatis tersebut dapat berkontribusi terhadap kejenuhan neurotransmisi parasimpatis termasuk di dalamnya pelepasan asetilkolin dan perubahan paska reseptor di nodus sinoatrial. ${ }^{11,15}$ Kannankeril et al. ${ }^{16}$ menyatakan bahwa pemberian atropin sebagai penghambat parasimpatis pada subjek dengan aktivitas fisik dapat meningkatkan denyut jantung.

Pada hasil penelitian ini didapatkan hasil yang bermakna $(P=0,025)$ untuk perbandingan PLJ antara subjek obes yang terlatih dengan subjek non-obes yang tidak terlatih. Subjek obes yang terlatih memiliki PLJ yang lebih baik daripada subjek nonobes yang tidak terlatih, sehingga dapat disimpulkan bahwa latihan fisik berperan penting terhadap nilai PLJ sehingga dapat diasumssikan menurunkan mortalitas terkait penyakit kardiovaskular. Lins et al. ${ }^{4}$ mendapatkan PLJ yang lebih rendah pada subjek obes dibandingkan dengan subjek non-obes $(P<0,001)$, tetapi tidak menyertakan tingkat latihan fisik. Barak et al. ${ }^{9}$ mendapatkan PLJ yang lebih tinggi pada subjek atlet dibandingkan dengan subjek non-atlet $(P<0,01)$ Cole et al. $^{17}$ mendapatkan individu yang memiliki PLJ $<42 \mathrm{x} /$ menit pada fase pemulihan menit ke2 memiliki angka mortalitas yang lebih tinggi dibandingkan dengan individu dengan PLJ $>42 \mathrm{x} /$ menit pada follow up 
tahun ke 12 dengan perbandingan 10\%: $4 \%$.

\section{SIMPULAN}

Subjek obes sentral yang terlatih memiliki PLJ yang lebih baik dibandingkan dengan subjek non-obes sentral yang tidak terlatih secara bermakna, yang menunjukkan faktor latihan fisik berperan penting dalam PLJ.

\section{SARAN}

Latihan fisik yang direkomendasikan oleh WHO sangat berperan penting pada kenormalan PLJ pada laki-laki usia muda. Untuk itu diharapkan peran dokter dalam edukasi pentingnya latihan fisik pada pasien dengan tujuan mengurangi mortalitas terutama akibat penyakit kardiovaskuler.

Dibutuhkan penelitian dengan sampel yang lebih banyak dan penelitian dengan perlakuan latihan fisik dan program penurunan berat badan dalam periode tertentu agar dapat menilai pengaruhnya pada PLJ.

\section{DAFTAR PUSTAKA}

1. Brinkworth GD, Noakes M, Buckley JD, Clifton PM. Weight loss improves heart rate recovery in overweight and obese men with features of metabolic syndrome. Am Heart J. 2006;7:1-6.

2. Tadjoedin Y, Suni I, Radi B. Disfungsi autonom pada pasien penyakit jantung hipertensi asimptomatik: hasil evaluasi pemulihan laju jantung. J Kardiol Indones. 2008;29:97-104.

3. Ostojic SM, Stojanovic MD, Gonzalez JC. Ultra short-term heart rate recovery after maximal exercise: relations to aerobic power in sportsmen. Chin $\mathrm{J}$ Physiol. 2011;54(2):105-10.

4. Tereza LBC, Valente LM, Filho DCS, Silva OB. Relation between heart rate recovery after exercise testing and body mass index. Rev Port Cardiol. 2015;34(1):27-33.

5. Nagashima J, Musha $H$, Takada $H$, Takagi K, Mita T, Mochida T, et al. Three-month exercise and weight loss program improves heart rate recovery in obese persons along with cardiopulmonary function. J Cardiol. 2010;56:79-84.

6. Watanabe J, Thamilarasan M, Blackstone E, Thomas J, Lauer M. Heart rate recovery immediately after treadmill exercise and left ventricular systolic dysfunction as predictors of mortality: the case of stress echocardiography. Circulation. 2001;104:1911-6.

7. Shetler K, Marcus R, Froelicher V, Vora S, Kalisetti D, Prakash M, et al. Heart rate recovery: validation and metodologic issues. J Am Coll Cardiol. 2001;38:1980-7.

8. WHO. Global recommendations on physical activity for health. 2010.

9. Barak OF, Ovcin ZB, Jakovljevic DG, Crvenkovic ZL, Brodie DA, Grujic NG. Heart rate recovery after submaximal exercise in four different recovery protocol in male athletes and non-athletes. J Sprots Sci Med. 2011;10:396-75.

10. Dhobie A, Lahr BD, Allison TG, Kopecky SL. Cardiopulmonary fitness and heart rate recovery as predictors of mortality in a referral population. J Am Heart Assoc. 2014;3:1-9.

11. Rahadyan A, Tajoedin Y, Radi B. Profil pemulihan laju jantung orang terlatih. J Kardiol Indones. 2008;29:20-4.

12. Goldberger J, Kiet FL, Lahiri M, Kannankeril PJ, Ng J, Kadish AH. Assessment of parasympathetic reactivation after exercise. Am J Physiol. 2006;290:2446-52.

13. Setianto B. Pemulihan laju jantung pada penyakit jantung hipertensi. J Kardiol Indones. 2008;29:105-6.

14. Javorka M, Balharek T, Javorka $K$. Heart rate recovery after exercise: relations to heart rate variability and complexity. Braz J Med Biol Res. 2002:35(8):991-1000.

15. Dewland TA, Androne AS, Lee FA, Lampert RJ, Katz SD. Effect of acetylcholinesterase inhibition with pyridostigmine on cardiac parasympathetic function in sedentary adults and trained athletes. Am J Physiol. 2007:293:86-92.

16. Kannankeril P, Le FK, Kadish A, Goldberger J. Parasympathetic 
Jurnal e-Clinic (eCl), Volume 5, Nomor 2, Juli-Desember 2017

effects on heart rate recovery after exercise. $\mathbf{J}$ Invest $\mathrm{Med}$. 2004;52(6):394-401.

17. Cole CR, Blackstone EH, Pashkow FJ,
Snader CE, Lauer MS. Heart rate recovery immidiately after exercise as a predictor or mortality. N Engl J Med. 1999;341:1351-7. 